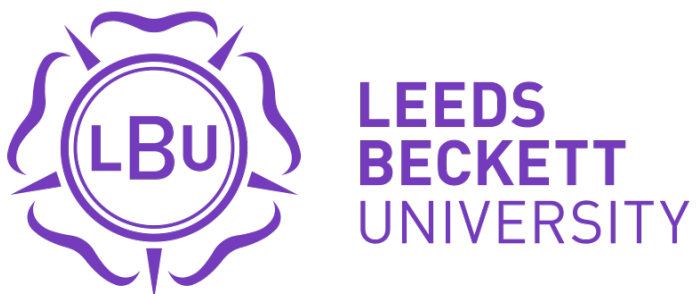

Citation:

Capps, DC and Stec, V and Tighe, M and Tinkler, H (2018) Training for the Bar - Educational (R)evolution. The Law Teacher. DOI: https://doi.org/10.1080/03069400.2018.1529271

Link to Leeds Beckett Repository record:

https://eprints.leedsbeckett.ac.uk/id/eprint/5449/

Document Version:

Article (Accepted Version)

The aim of the Leeds Beckett Repository is to provide open access to our research, as required by funder policies and permitted by publishers and copyright law.

The Leeds Beckett repository holds a wide range of publications, each of which has been checked for copyright and the relevant embargo period has been applied by the Research Services team.

We operate on a standard take-down policy. If you are the author or publisher of an output and you would like it removed from the repository, please contact us and we will investigate on a case-by-case basis.

Each thesis in the repository has been cleared where necessary by the author for third party copyright. If you would like a thesis to be removed from the repository or believe there is an issue with copyright, please contact us on openaccess@leedsbeckett.ac.uk and we will investigate on a case-by-case basis. 


\title{
Training for the Bar: Educational (R)evolution
}

\author{
Deveral Capps, Victoria Stec, Maria Tighe, Helen Tinkler.
}

Deveral Capps, Leeds Law School, Leeds Beckett University, Leeds, England; Victoria Stec, Bar Standards Board, London, England, Maria Tighe, Professor Emerita, Educational Consultant, Leeds, England; Helen Tinkler, Educational Consultant, Birmingham, England.

Corresponding author: - Deveral Capps, Dean, Leeds Law School, Leeds Beckett University, Leeds, West Yorkshire, LS1 3HE. email: - d.capps@leedsbeckett.ac.uk.

\begin{abstract}
On $25^{\text {th }}$ June 2013, the Legal Education and Training Review published its report on the legal education landscape and made 26 recommendations for change. Over the past 5 years the legal regulators have considered these recommendations and developed and consulted on new education and training pathways and assessment strategies. This article focusses on the Bar Standards Board's Future Bar Training Programme and provides commentary, explanation and a rationale for training for the Bar from 2020.
\end{abstract}

Keywords - Barrister, Education and Training, International Students, Legal Education, Barristers training, BPTC, BVC.

\section{Introduction}

On $25^{\text {th }}$ June 2013, the Legal Education and Training Review published its report on the legal education landscape and suggested certain changes be made to ensure the legal training regime met the needs of future legal services provision and regulatory oversight. ${ }^{1}$ LETR, as the Legal Education and Training Review came to be known, was funded by the three main legal regulatory bodies: The Solicitors Regulation Authority, the Bar Standards Board and CILEx Regulation ${ }^{2}$. It was the largest review of its kind since Lord Justice Ormrod's review in $1971^{3}$ and made a total of 26 recommendations across all aspects of legal and professional study. Now, 5 years on, many of these recommendations are becoming clearly visible on the horizon and this article will focus specifically on those changes soon to be implemented for those who wish to qualify as barristers.

At the outset, it should be made clear that the content of this article refers solely to training as a barrister in England and Wales. Whilst Northern Ireland and Scotland are part of the United Kingdom, they are separate legal jurisdictions, have different legal training programmes and in the case of Scotland have the title of advocate rather than barrister. It should also be noted

Setting Standards: The future of legal services education and training regulation in England and Wales, The Legal Education and

Training Review, 2013 < http://www.letr.org.uk/the-report/ > accessed 20th September 2018.

At the time of the report, CILEx Regulation was known as ILEX Professional Standards.

Report of the Committee on Legal Education, (Cm 4595, 1971). 
that the training position is accurate as at the time of going to press, $1^{\text {st }}$ September 2018. Whilst the Bar Standards Board ("BSB") has approved all of the changes referred to in this article, ${ }^{4}$ the rule changes enabling this evolution are subject to Legal Services Board approval.

\section{Setting the scene - useful statistics on barristers in the UK and abroad}

According to figures from the BSB in 2017 there were 16,435 barristers holding practising certificates for England and Wales. ${ }^{5}$ Whilst these figures might appear low when compared with the 143,184 practising solicitors as of July $2018,{ }^{6}$ the BSB figure does not show the large number of individuals within the UK or around the world who have been called to the Bar but not in independent practice within England and Wales.

Qualifying as a barrister continues to be popular and each year there are almost 3000 applications for the Bar Professional Training Course ("BPTC") with around 50\% of all applications leading to course enrolment.

$\begin{array}{lllllll}\text { Year } & \mathbf{2 0 1 1} & \mathbf{2 0 1 2} & \mathbf{2 0 1 3} & \mathbf{2 0 1 4} & \mathbf{2 0 1 5} & \mathbf{2 0 1 6} \\ \text { Applications } & 3017 & 3026 & 2730 & 2660 & 2910 & 2917 \\ \text { Enrolments } & 1665 & 1698 & 1534 & 1495 & 1400 & 1424\end{array}$

As further figures from the BSB below show, the qualification of barrister is very attractive to international students and there is an increasing proportion of non-EU students undertaking the BPTC programme. Of these non-EU students, Malaysia, Bangladesh, Mauritius and Pakistan provide the greatest number of Bar students. ${ }^{7}$

$\begin{array}{lrrrrrr}\text { Year } & \mathbf{2 0 1 1} & \mathbf{2 0 1 2} & \mathbf{2 0 1 3} & \mathbf{2 0 1 4} & \mathbf{2 0 1 5} & \mathbf{2 0 1 6} \\ \text { UK/EU } & 1134 & 1054 & 964 & 884 & 798 & 809 \\ \text { Overseas } & 530 & 642 & 570 & 606 & 598 & 613 \\ \text { Not provided } & 1 & 2 & & <10 & <5 & <5\end{array}$

Further figures on bar training can be found in the BSB's Key Statistics $2018^{8}$

on $17^{\text {th }}$ May 2018.

Practising barrister statistics, Bar Standards Board <www.barstandardsboard.org.uk/media-centre/research-andstatistics/statistics/practising-barrister-statistics/> accessed 20th September 2018.

Regulated population statistics, <https://www.sra.org.uk/sra/how-we-work/reports/data/population_solicitors.page> a accessed 20th September 2018.

Of the 4319 students who enrolled on a BPTC between 2014-16, 2161 were UK Nationals, 915 were from Malaysia, 329 from Bangladesh, 179 from Mauritius and 175 from Pakistan. Figures provided by the BSB on request.

Bar Standards Board Key Statistics 2018 - an analysis of students over three academic years,

<https://www.barstandardsboard.org.uk/media/1932232/bptc key statistics report_2018.pdf> accessed 20th September 2018. 


\section{Background to Future Bar Training}

The Future Bar Training ("FBT") programme commenced in 2014 and should be seen in the context of three specific reviews (a Review of the Bar Vocational Course, ${ }^{9}$ a Review of Pupillage $^{10}$ and a Review of Continuing Professional Development ${ }^{11}$ ) that pre-date LETR undertaken by Derek Wood QC between 2008-2010 and, of course LETR ${ }^{12}$ itself. FBT develops a regulatory approach that is risk-based and outcomes-focused that aligns with the outcomes of the LETR. A Professional Statement for Barristers Incorporating the Threshold Standard and Competences was published in 2016 defining the 'day one' competences expected of a barrister, ${ }^{13}$ and a new, less prescriptive and more outcomes-focused CPD regime was introduced in January 2017. ${ }^{14}$

In March 2017, the BSB issued a policy statement indicating that a limited number of pathways ${ }^{15}$ for training as a barrister would be permitted, provided that any proposed pathway could demonstrate it addressed four core FBT principles of flexibility, accessibility, affordability and sustaining high standards. ${ }^{16}$ The policy statement reflected a more holistic approach to training for the Bar in that the linear notion of 'stages' of training was replaced by the concept of 'components', which might, in some instances, be integrated. The four permitted pathways ${ }^{17}$ opened up a wider range of potential training routes than the current single prescribed route to the Bar.

The FBT programme is intended to enable the BSB to fulfil its statutory objective of encouraging an independent, strong, diverse and effective legal profession so that there are barristers who can meet the needs of consumers in a fast-changing market for legal services.

\footnotetext{
Bar Standards Board, Review of the Bar Vocational Course, Report of the Working Group, 2008,

<https://www.barstandardsboard.org.uk/media/1353435/bvc report final with annexes as on website.pdf $>$ accessed 20th September 2018.

Bar Standards Board, Review of Continuing Professional Development, 2011,

<https://www.barstandardsboard.org.uk/media/938837/cpd_consultation_-_31_may_2011_final.pdf> accessed 20th September 2018 .

12 LETR, $\mathrm{n} 1$

13 Bar Standards Board, Future Bar Training Professional Statement for Barristers incorporating the Threshold Standard and Competences,

<https://www.barstandardsboard.org.uk/media/1787559/bsb_professional_statement_and_competences_2016.pdf> accessed 20 th September 2018 .

14 Bar Standards Board, Continuing Professional Development from ${ }^{\text {st }}$ January 2017,

<https://www.barstandardsboard.org.uk/regulatory-requirements/for-barristers/continuing-professional-development-from-1january-2017/> accessed 20th September 2018.

15 These pathways are: a single vocational course much similar to the current BPTC, a two-part vocational training model separating knowledge from skills, a combined academic and vocational training model and a modular or apprenticeship training model. Bar Standards Board policy statement on Bar Training,

<https://www.barstandardsboard.org.uk/media/1825162/032317 fbt - policy statement version for publication.pdf > accessed 20 th September 2018 
FBT is informed by the Legal Services Board's statutory guidance, Guidance on regulatory arrangements for education and training issued under s162 Legal Services Act 2007 on $4^{\text {th }}$ March 2014, ${ }^{18}$ and their standards for assessing regulatory performance, Regulatory Performance Standards issued in December 2017. ${ }^{19}$ By enabling a range of managed pathways, it is hoped that innovation in the market will be stimulated, without the risk of an unmanageable and potentially confusing proliferation of training routes.

\section{The various projects/review groups}

Workstreams that fell under FBT included a Rule Change Project, a Pupillage Reform Project, a project on the Role of the Inns and a Programme Evaluation Project. Most pertinent to this paper are two further projects: The Authorisation Framework and the Curriculum and Assessments Review (“CAR"). The Authorisation Framework provides a means for training providers to demonstrate their fitness to deliver an approved pathway, by fulfilling a range of criteria, and specifically it prescribes how they will demonstrate that high standards are addressed and sustained through a high-level Curriculum and Assessment Strategy. The aim of the Curriculum and Assessment Strategy is to ensure that prospective barristers meet the requirements of the Professional Statement and Threshold Standard ${ }^{20}$ by following permitted pathways at Authorised Education and Training Organisations (“AETOs").

Proposals from intending training providers will need to be successfully tested against the Framework and found to comply with the Curriculum and Assessment Strategy before the status of Authorised Education and Training Provider (“AETO”) may be granted.

As part of the process of drafting the Authorisation Framework, an exercise was undertaken to map it across to the new regulatory framework for Higher Education in England published by the Office for Students ("OfS") in February 2018. ${ }^{21}$ This exercise was to ensure both alignment, and that the BSB understands the obligations under the OfS framework of AETOs registered with the OfS who wish to deliver the academic and vocational components. The BSB will then be clear where it can rely on AETO compliance with OfS requirements as a proxy for the BSB's own, thus saving duplication and reducing the regulatory burden on AETOs.

\section{Curriculum and Assessments Review Group ("CAR")}

\footnotetext{
18 Legal Services Board, Guidance on regulatory arrangements for education and training issued under section 162 of the Legal Services Act 2007,

<http://www.legalservicesboard.org.uk/what we do/regulation/pdf/20140304 LSB Education And Training Guidance.pdf> accessed 20th September 2018.

19 Legal Services Board, Regulatory Performance Assessment: Regulatory Performance Assessment <http://www.legalservicesboard.org.uk/news publications/LSB news/PDF/2017/Regulatory Performance Standards December 2017 (final).pdf $>$ accessed 20th September 2018.

20 Bar Standards Board, Future Bar Training Professional Statement for Barristers incorporating the Threshold Standard and Competences, $\mathrm{n} 8$.

$21 \quad$ Office for Students, Securing student success: Regulatory Framework for Higher Education in England, February 2018, <https://www.officeforstudents.org.uk/media/1406/ofs2018 01.pdf> accessed 20th September 2018.
} 
Following the publication of the Policy Statement on the Future of Bar Training in March $2017,{ }^{22}$ a thorough review of the vocational stage of training was proposed as part of the FBT programme and the drive towards training reform. The review would focus on the area that is currently the vocational stage of training covered by the Bar Professional Training Course (“BPTC").

The current curriculum and assessment strategy was designed before the Professional Statement for Barristers was introduced in $2017,{ }^{23}$ and as such, a review was timely to ensure that the curriculum and assessments underpinned the Professional Statement. In particular, a commitment to review the way in which Professional Ethics is taught and assessed was contained in the Policy Statement, given the concerns raised by external research about the ethical capabilities of newly qualified advocates. ${ }^{24}$

In April 2017 a CAR group was convened comprising key BSB staff (Dr Vanessa Davies, Dr Victoria Stec, Natasha Ribeiro and Hayley Langan) and three academic experts in curriculum and assessment: Deveral Capps (Dean of Leeds Law School, Leeds Beckett University), Professor Maria Tighe (Professor Emerita and Consultant to the BSB) and Helen Tinkler (Assistant Chief Examiner (Civil) for the BSB). Professor Mike Molan (Chair of the Centralised Examinations Board) joined CAR in February 2018.

At an early stage, it was clear to CAR that the vocational component could not be seen in isolation from other parts of a barrister's training, and a concurrent review of all aspects of the training regime before full qualification was also required. As such, all compulsory courses prescribed during pupillage were brought within its scope. CAR aimed to:

- create a curriculum defining which competences should be met, either fully or partially, during the vocational and work-based learning component and determine what students need to do in order to meet them;

- identify elements of the curriculum that should be prescribed;

- decide what the curriculum should look like to ensure students develop the necessary range of competences;

- determine which assessments should be centrally set and assessed; and

- construct an appropriate and contemporary assessment strategy to enable students to demonstrate appropriate skill and knowledge competences.

\footnotetext{
22 Bar Standards Board, Policy Statement on Future Bar Training, March 2017,

〈https://www.barstandardsboard.org.uk/media/1825162/032317 fbt - policy statement version for publication.pdf > accessed 20th September 2018.

23 Bar Standards Board, Future Bar Training Professional Statement for Barristers incorporating the Threshold Standard and Competences, $\mathrm{n} 8$.

24 Ethical Capacities of New Advocates, Centre for Ethics and Law, Richard Moorhead, Catrina Denvir, Mark Sefton and Nigel Balmer <https://www.icca.ac.uk/images/download/ethics/moorhead-et-al-2015-ethical-capacities-of-new-advocates-finalreport.pdf > accessed 20th September 2018.
} 
Pivotal to the review were the keystone objectives for the whole of the FBT programme, these being:

- encouraging greater flexibility - so the system enables innovation in how education and training is delivered;

- improving accessibility - so the best candidates, regardless of background, will train as barristers thereby ensuring the Bar as a whole better reflects the communities it serves;

- increasing affordability - to bring down the cost of studying to students where possible, and to increase value for money, for instance in terms of employability, that justify the cost; and

- ensuring high standards - to guarantee all barristers, regardless of which training pathway is chosen, qualify to agreed standards.

\section{Methodology and Evidence for change - Documentary evidence and data}

The requirements of the Professional Statement underpinned the Curriculum and Assessments review. In addition, CAR had access to the extensive portfolio of evidence that had informed previous aspects of Future Bar Training. CAR also reviewed research reports, focus group evidence, read external examiners' reports and captured their views through a purposefullyfocused questionnaire. In addition, and with the permission of current BPTC providers, all provider-set assessments for the 2016/2017 academic year were reviewed.

Our review of existing evidence included the following key pieces:

- The Legal Education and Training Review $2013^{25}$

- BPTC and Pupillage Focus Group Research Report 2015.

- Ethics Report: The Ethical Capacities of New Advocates 2015. ${ }^{26}$

- BPTC Sub-Committee: Future of Options 2015.

- Exploring differential attainment at BPTC and Pupillage: A quantitative study. ${ }^{27}$

- CAR group questionnaire to External Examiners 2017.

口 The reports of the Chair of the BSB Central Examinations Board. ${ }^{28}$

- Written correspondence with the Committee of Heads of University Law Schools and the Association of Law Teachers.

\section{Consultations}

\footnotetext{
25 Setting Standards: The future of legal services education and training regulation in England and Wales, The Legal Education and Training Review, n 1.

$26 \quad$ Ethical Capacities of New Advocates, n 19.

27 Bar Standards Board, Exploring differential attainment at BPTC and Pupillage: A quantitative study, November 2017, <https://www.barstandardsboard.org.uk/media/1910429/differential attainment at bptc and pupillage analysis.pdf > accessed 20th September 2018.

28 Bar Standards Board Central Examination Board, Chair's Reports, <https://www.barstandardsboard.org.uk/qualifying-as-abarrister/current-requirements/bar-professional-training-course/bptc-centralised-examinations/chair's-report/> accessed 20th September 2018.
} 
To maximise collaboration in the review process, an invitation was extended to BPTC providers to engage with CAR directly and a discrete session took place at the BPTC Conference in July 2017 where delegates were invited to question and comment upon emerging findings. A member of CAR also attended the regular BPTC Provider meetings held during the course of the 2017/2018 academic year to ensure the dialogue with providers continued as CAR's recommendations evolved.

Comments were also invited from pupil supervisors through the Pupil Supervisor Network regarding their view of pupils' preparedness for pupillage. In addition, two roundtables were held early in August 2017 with pupil supervisors and separately with recent or current pupils and newly qualified barristers. For each of these a series of focused questions were prepared. At each meeting, both chambers and in house were represented. On $13^{\text {th }}$ February 2018, an event was held in London to speak to current BPTC students from all current providers and hear their views on the existing training approach.

\section{The current training regime}

Before examining how someone will train to be a barrister from September 2020 onwards, it would be sensible to briefly describe how barristers currently qualify. In short, those who wish to go to the Bar must pass three distinct stages: an academic stage, a vocational stage and pupillage. The requirements for the academic stage are met once a candidate has obtained either a qualifying law degree ("QLD”) or, for those who already hold an undergraduate degree in different discipline, a Graduate Diploma in Law. ${ }^{29}$ The academic stage must comply with the requirements of the 'Joint Statement' issued by the Joint Academic Stage Board ("JASB"). ${ }^{30}$ Before a student undertakes the BPTC they must first pass a Bar Course Aptitude Test better known as BCAT, ${ }^{31}$ and join an Inn of Court.

The vocational stage of training is heavily prescribed. Overseen and regulated by the Bar Standards Board ("BSB") prospective barristers must complete the BPTC at one of eight institutions in England and Wales. ${ }^{32}$ Currently, the BPTC can be completed as a full-time course over one year or as a part-time course spread over two years as either day-release or weekend study. The BPTC also exists as 4-year degree programme that integrates the academic and vocational stages. ${ }^{33}$

\footnotetext{
29 The Graduate Diploma in Law is also known as the Common Professional Exam.

30 Bar Standards Board and the Solicitors Regulation Authority, Academic Stage Handbook, <https://www.sra.org.uk/documents/students/academic-stage/academic-stage-handbook.pdf> accessed 20th September 2018.

31 Further information about the Bar Course Aptitude Test can be found at <https://www.barstandardsboard.org.uk/qualifying-as-abarrister/current-requirements/bar-professional-training-course/bar-course-aptitude-test/> accessed 20th September 2018.

32 The institutions currently offering the BPTC are: BPP University (in Birmingham, Leeds, Bristol, London and Manchester), Cardiff University, City University of London, Northumbria University, Nottingham Trent University, University of Law (in Birmingham, London and Leeds), University of the West of England and Manchester Metropolitan University.

33 Northumbria University is the only institution currently to offer an integrated approach.
} 
Regardless of the mode of study the BSB specifies in broad terms the assessment strategy to be followed. There are 12 assessments that can be separated into knowledge and skills.

\section{Bar Professional Training Course (2011-2020)}

\section{Knowledge}

- Criminal Litigation, Evidence and Sentencing (3-hour exam)

- Civil Litigation and Evidence (3hour exam)

- Professional Ethics (2⿺辶⿸厃㔾 hour exam)

- Resolution of Disputes Out of Court (exam)

\author{
Skills \\ - 3 x Advocacy Assessments (practical) \\ - Drafting Skills (exam) \\ - Opinion Writing (exam) \\ - Conference Skills (practical) \\ - 2 x Options (practical)
}

To add a little colour to the above: the three advocacy assessments comprise a civil submission, examination-in-chief and cross-examination; BPTC providers are required to offer 2 options/electives to students; save for Resolution of Disputes out of Court ("ReDoC") all of the knowledge assessments are centrally set by the BSB and marked and moderated by a BSBappointed team. Students must pass each assessment to at least $60 \%$ to pass the BPTC and be called to the Bar by their Inn of Court. Once called, the individual is permitted to use the title of barrister, though in order to practise law independently and be known as a barrister-at-law, pupillage must be completed.

Pupillage represents the final part of a barrister's training that follows the BPTC where, most commonly, a 'pupil' works in a set of barristers' chambers with a pupil supervisor. Pupillage is normally of twelve months in duration and divided into two, 6-month periods known as a first six (non-practising) and second six (practising). ${ }^{34}$ During this 12-month period, and in addition to pupillage checklists ensuring exposure to range of appropriate tasks, ${ }^{35}$ a pupil needs to complete an advocacy course, a practice management course and a forensic accounting course. $^{36}$

\section{The proposed Curriculum and Assessment Changes}

During the review, a large number of changes were suggested, considered and discussed for the vocational component and after 12 months, CAR arrived at a consensus accepted by the BSB. The Board had already concluded that the three components should be retained, but these

\footnotetext{
34 Details about the structure and requirements of pupillage can be found here - <https://www.barstandardsboard.org.uk/qualifyingas-a-barrister/current-requirements/pupillage/structure-of-pupillage/> accessed 20th September 2018.

Bar Standards Board, Pupillage Handbook, Chapter 9

<https://www.barstandardsboard.org.uk/media/1841538/bsb pupillage handbook 2017 1.8.17.pdf $>$ accessed 20th September 2018 .

36 Bar Standards Board, Training during Pupillage < https://www.barstandardsboard.org.uk/qualifying-as-a-barrister/currentrequirements/pupillage/training-during-pupillage/> accessed 20th September 2018. The forensic accounting course needs to be completed within the first 3 years of practice.
} 
would no longer be seen as sequential stages, allowing for integration in line with the potential opportunities offered by the new pathways.

\section{The Academic Component}

The BSB and the SRA agreed a common protocol early in $2018 ;{ }^{37}$ the full requirements of the Qualifying Law Degree will fall away but the BSB has retained the requirement for the seven foundations of legal knowledge subjects to be studied prior to undertaking the vocational component. These subjects must be studied at an institution that complies with the QAA subject benchmark for law $^{38}$ and ensuring that a candidate possesses the relevant qualifications is a responsibility that rests with the AETO.

\section{The Vocational Component}

In order to meet the requirements of the Professional Statement, the majority of the changes recommended by CAR have manifested themselves in the vocational component of Bar training. The table below lists the new curriculum and assessment strategy. Underlined assessments are new and those with a strikethrough no longer appear in the vocational component.

\section{Vocational Component (September 2020 onwards)}

\section{Knowledge}

- Criminal Litigation,

Evidence and Sentencing (3-

hour exam)

- Civil Litigation and

Evidence (3-hour exam)

- Civil Dispute Resolution

(exam)

Professional Ethies (21/2

hour exam)

-Resolution of Disputes Out

of Court (exam)

\author{
Skills \\ - 3 x Advocacy Assessments \\ (practical) \\ - Drafting Skills (exam) \\ - Opinion Writing (practical) \\ - Legal Research (practical) \\ - Conference Skills (practical) \\ - Professional Ethics
}

\section{Professional Ethics}

The knowledge aspect of the vocational stage the closed book, short answer question exam has been moved to the work-based learning component of barristers' training. CAR felt, and the evidence received was compelling, that the assessment of ethics should run through the whole

Bar Standards Board and Solicitors Regulation Authority, Common Protocol on the Academic Stage of Training

<https://www.barstandardsboard.org.uk/qualifying-as-a-barrister/current-requirements/academic-stage/common-protocol-on-theacademic-stage-of-training/ > accessed 20th September 2018.

38 Quality Assurance Agency for Higher Education, Subject Benchmark for Law, July 2015

<http://www.qaa.ac.uk/docs/qaa/subject-benchmark-statements/sbs-law-15.pdf?sfvrsn=ff99f781 8 $>$ accessed 20th September 2018 . 
of a barrister's training. As such, having an assessment within both the vocational stage and the work-based learning stage was deemed appropriate. AETOs will be free to set an appropriate assessment to ensure that candidates are fit for call to the Bar and an open book BSB centrally set and marked assessment will be taken during the work-based learning component to ensure the required standard for full qualification.

\section{Civil Dispute Resolution}

As part of the evidence gathering stage, CAR reviewed all assessment instruments for the Resolution of Disputes Out of Court ("ReDoC") across all providers. In order to ensure high standards and a common approach to the assessment of required knowledge, the REDOC syllabus was subsumed into a new Civil Dispute Resolution (“CDR") Paper. Evidence put before CAR suggested that the public would benefit from an assurance that newly qualified barristers also have a solid knowledge of costs. CAR also determined to make the CDR an open book exam, the logistics of which are to be decided. This will better reflect the reality of practice.

\section{Opinion Writing and Drafting}

For many years Opinion Writing and Drafting have been assessed by way of examination simply to prevent assessment irregularities in the form of collusion and plagiarism. Given the advances made over the last decade and the extensive use of Turnitin ${ }^{39}$ and other academic similarity software, and widespread acceptance of electronic submission by students, CAR considered it appropriate for Opinion Writing to move to a take-home style assessment that would simulate the realities of practice. The use of academic similarity software would help ensure it is the prospective barrister's own work. CAR did not feel that this would be appropriate for drafting, given the likelihood of a high similarity index between candidates who had not engaged in any academic malpractice.

\section{Legal Research}

The Professional Statement requires a barrister be competent in legal research. Given that legal research was not assessed discretely on the BPTC, CAR felt it must be reintroduced. ${ }^{40}$ CAR recommended legal research be assessed alongside the revised opinion writing assessment and did so for two main reasons. First, it would make the assessment of opinion writing more realistic because in order to properly prepare and advise, a barrister must ensure what is written is accurate. Secondly, assessing legal research alongside opinion writing will reduce the assessment burden on both AETOs and students and thereby help to make the Bar Course more affordable.

Dual assessment does, however, have a downside, sometimes referred to as a 'critical' or 'mortal' wound; a significant mistake in one assessment could carry over to the second assessment resulting in the student failing both. Whilst certainly a risk, this sort of error is,

\footnotetext{
$39 \quad$ https://www.turnitin.com/

40 Legal Research was assessed on the Bar Vocational Course - the forerunner to the BPTC.
} 
again, realistic of practice and helps reinforce the imperative of solid legal research at the outset.

\section{Options}

Options have been part of the Bar course for many years, with students choosing to undertake either two single options or in some cases a larger double option. CAR found little support from the Bar around options, that they appeared to have limited real value on pupillage selection procedures and sometimes hampered it. If AETOs wished to offer options as part of their course, for example to provide a unique selling point or to add value, CAR saw no reason for them being prevented from doing so but in order to improve affordability, flexibility and foster innovation options would not be mandated by the BSB.

\section{Advocacy and Conference Skills}

CAR concluded following a review of the evidence that Advocacy Skills and Conference skills ${ }^{41}$ were both essential to the vocational component and currently assessed appropriately. The only changes recommended for these two skills are that there should be a greater degree of uniformity between the assessment methods and assessment criteria to ensure a greater degree of consistency between assessments at AETOs.

\section{Miscellaneous changes}

Bar assessment guidelines. As noted above, part of the evidence base that helped CAR form conclusions included a detailed review of all current assessments at BPTC providers. Conclusions were that there were notable differences between assessments in length, in complexity, in what a student was expected to do within any particular timescale as well as the criteria they were being measured against. Whilst each assessment was fit for purpose, there was a risk a student might fail at one provider yet pass at another and, as such, CAR recommended the creation of Bar assessment guidelines to ensure all who undertake the vocational component will be measured against the same yardstick. These guidelines will suggest parameters for the lengths of assessments and preparatory materials and ensure all students are marked against identical assessment criteria. The guidelines will be developed with the input of AETOs and reviewed annually.

Skills-based lead external examiners. A system of subject lead external examiners will be introduced to supplement the existing external examiner team. Subject leads will have oversight across all AETOs, to review locally set assessments in accordance with the Bar Assessment Guidelines and to ensure equal rigour in assessments, assessment moderation and student marking. This represents a significant evolution of the current system of external examining.

A 5-year completion period. Prospective barristers commencing training from 2020 will need to pass the vocational component assessments within a 5-year window. In terms of flexibility, accessibility and affordability, this will assist with the burden of study, financial and otherwise

A conference is a term used to describe a meeting between a barrister and lay/professional client. 
from individuals who are balancing work and family commitments. AETOs' regulations will determine the number of resits available to a candidate, with the BSB stipulating only that completion of all assessments must be within five years.

\section{Pupillage or the Work-Based Learning Component}

The work-based learning ("WBL") component, a term that encompasses 'pupillage', will not change dramatically. ${ }^{42}$ It still comprises practical learning supervised by an experienced professional but will ensure a stronger link between the professional statement and training, and a consistency of outcomes regardless of how the WBL component will be completed; something clearly relevant now barrister apprenticeships have been enabled as a potential pathway.

CAR's remit extended to the mandatory courses undertaken during pupillage. As part of the new training requirements, the practice management and forensic accounting courses will no longer be required; practice management will be covered by the AETO in the context of practice whereas forensic accounting competence is not required by the professional statement and so is no longer prescribed. The Pupils' Advocacy Course will remain, albeit with a greater quality assurance oversight, mainly because CAR felt such refresher training essential before a pupil stepped foot in a court room or tribunal and represented clients with their provisional practising certificate. This, it was felt, was especially important when considering that many pupils experienced a significant time-gap between finishing their Bar Course and commencing WBL.

The most significant changes within the work-based learning stage come with the reintroduction of a negotiation skills practical assessment and a summative Professional Ethics examination.

Negotiation Skills was assessed on the BPTC's forerunner, the Bar Vocational Course (running between 1989 and 2010 but was removed from the BPTC following the Wood Review. ${ }^{43}$ Negotiation skills as taught on the BVC was viewed as synthetic and unrealistic and so by placing the summative assessment during pupillage, when pupils have had the opportunity to see negotiations operating in practice, will promote realism.

The introduction of a final summative assessment in Professional Ethics prior to full qualification is because of the perceived ethical weaknesses in junior practitioners as identified in the Ethics Report: Ethical Capacities of New Advocates 2015. ${ }^{44}$ In this report, following a survey of newly qualified practitioners who were placed in ethical dilemmas, "About half the

\footnotetext{
42 Although the payment of the living wage to pupils will be most welcomed by those undertaking WBL. Future Bar Training: BSB Policy Statement on pupillage and other forms of work-based learning, the authorisation framework, and the curriculum and assessment strategy, <https://www.barstandardsboard.org.uk/media/1935316/fbt_pupillage_af_and_car_policy_statement__may18.pdf>, page 4, accessed 20th September 2018.

43 Bar Standards Board, Review of the Bar Vocational Course, Report of the Working Group, 2008, n 5.

$44 \quad$ Ethical Capacities of New Advocates, n 19
} 
cohort of interviewees performed well or reasonably well; a third performed well only about half the time and the remaining proportion generally performed poorly." 45 Whilst the precise format of the final assessment has yet to be determined, early indicators suggest that this will be an open book examination. The assessment will be centrally assessed and in order for a pupil to be able to properly address the learning outcomes, it cannot be taken before at least six weeks of their pupillage/work-based learning component have elapsed.

\section{The centralised assessments Civil Litigation and Evidence, Criminal Litigation Evidence and Sentencing, and Professional Ethics on the BPTC}

The responsibility of CAR in determining the new assessment strategy weighed heavily throughout and none more so than in relation to the centralised summative assessment of civil litigation, criminal litigation and professional ethics. In the BSB's Policy Statement of March $2017,{ }^{46}$ the BSB confirmed that it would continue to control a range of centralised assessments: "so that so that the public is assured of a consistency in "day one" outcomes: that whatever route a barrister took to being called to the Bar and subsequently being awarded their first practising certificate, a minimum standard of competence, skill and knowledge has been achieved."

\section{Centralised assessment}

Until 2010-11, BPTC Providers were required to assess candidates in Professional Ethics, Civil Litigation and Criminal Litigation (the "knowledge areas") by means of locally set and marked multiple-choice questions ("MCQs") and short answer questions ("SAQs"). Centralising these assessments was a key recommendation of the Wood Report ${ }^{47}$ and the Centralised Examinations Board ("CEB") was established to oversee this change on behalf of the BSB and set and mark the assessments. 2011-12 was the first year of operation for the system of centralised assessment

From the 2011-12 academic year, up to and including the 2015-16 academic year, candidates in each of the three centrally assessed subjects were required to attempt an MCQ test and an SAQ test. All questions were compulsory and the pass mark in each paper fixed at $60 \%$; all MCQ papers were marked electronically using Speedwell scanning technology. SAQ papers were marked by teaching staff at the relevant Provider institution, with marks remitted to the CEB for processing. Marks for the MCQ and SAQ papers were aggregated to provide each candidate with a combined mark for each assessment with a requirement that candidates were required to achieve the pass mark of $60 \%$ in both elements of each assessment, there being no scope for the aggregation of marks below $60 \%$ between MCQ and SAQ scores to achieve the minimum $60 \%$ pass mark overall.

\footnotetext{
$45 \quad$ Ethical Capacities of New Advocates, n 19, page 94.

46 BSB Policy Statement on Bar Training, March 2017, <https://www.barstandardsboard.org.uk/media/1825162/032317_fbt__policy statement version for publication.pdf $>$, accessed 20th September 2018.

Bar Standards Board, Review of the Bar Vocational Course, Report of the Working Group, 2008, n 5, para 147-149.
} 
For the academic year 2017-18, acting on the recommendations of the BSB's Education and Training Committee and following concerns in terms of the reliability and consistency of provider SAQ marking, the CEB introduced significant changes to the format and marking processes for the centralised assessments on the BPTC. ${ }^{48}$

Both the Civil Litigation and Criminal Litigation assessments were modified to become threehour papers comprising $75 \mathrm{MCQ}$ and Single Best Answer ("SBA") questions. This change meant that the answers for the entire paper in both subject areas could be marked electronically using Speedwell scanning technology. The assessment in Professional Ethics became a twohour paper comprised of six SAQs, the marking being undertaken by a team of independent markers appointed by the BSB. From spring 2018, the length of the assessment was increased to $2 \frac{1}{2}$ hours.

Although the BSB will continue to control assessment of the knowledge areas, CAR nonetheless considered the extent to which centralised assessments continue to be valid for the purpose of drawing a correct inference that a successful student has reliably demonstrated appropriate skills attitude and competence, and knowledge of procedure and evidence. CAR was conscious that, due to the sheer amount of information required to be absorbed for the knowledge areas on the BPTC, learning struggles to be embedded as a cognitive-constructivist skill, ${ }^{49}$ although the range and scope of the tools of assessments by MCQs, SBAs should reassure on that count as they allow consideration of likelihood of outcomes, a balancing of issues and the giving of best advice based upon evaluative judgment. Computer marking also enhances reliability as it ensures consistency as there is no need for a subjective, impressionistic, value judgment by a marker working to a marking scheme. It enables "the same or very similar scores for the same students at different times in different places and regardless of who is marking the assessment". ${ }^{50}$

The BPTC is a summative vocational qualification at the end of which, the learner is deemed ready for pupillage. It was, therefore, an important consideration as to how well the BPTC prepared the student for pupillage. This is particularly pertinent and shows through in CAR's facilitation of the number of attempts to maximise the chance of success. We were also conscious of the market place approach to alternative dispute resolution hence widening the scope of the civil litigation centralised assessment to accommodate ReDoC in the knowledge area and more natural home.

Further, the more pervasive assessment of ethics reflects that appropriate conduct is an everpresent consideration. CAR's refinements aim for more consistent control over breadth and depth of coverage of the syllabuses, which in turn permits appropriate construct representation to allow a stronger inference of validity to be drawn and says something positive about the

\footnotetext{
$48 \quad$ Bar Standards Board Central Examinations Board Chairs Report August 2016 <https://www.barstandardsboard.org.uk/media/1777378/2015-16_first_sit_chair_s_report.pdf> accessed 20th September 2018.

49 James, M. Assessment and Learning, in Swaffield, S. (Ed.) Unlocking Assessment: Understanding for reflection and application, at page 25, Abingdon: Routledge. 
underlying depth and extent of embedded functional learning. Criminal Litigation and Civil Litigation will continue as 'closed book' assessments comprising MCQs and SBAs with Civil Dispute Resolution being 'open book'. The 'closed book' assessment will test knowledge that the BSB feel is essential knowledge and application whereas the 'open book' can test wider and more specialist knowledge with the ability to navigate permitted materials.

CAR has worked to deliver on the FBT programme's principles to allow all BPTC students to be treated fairly and to have an equal prospect of success assessed with reference to their true ability, merit and competence.

\section{Conclusion and next steps}

After a short consultation from July to September 2018 on the proposed rule changes that are needed to enable training reform, ${ }^{51}$ the BSB will make a submission to the Legal Services Board and, subject to approval, the new rules will come into effect from early 2019. This means that proposals from intending AETOs may then be submitted. Details of the precise dates for implementation of all aspects of the Curriculum and Assessment Strategy are still under discussion, but it is likely that the last academic year for delivery of the current BPTC will be 2019-20.

The BSB has had confidential discussions with each of the current BPTC providers about the nature of the proposals likely to come forward and it is clear the changes referred to above will help achieve all of the keystones identified in the original FBT policy documentation. A detailed dialogue is also underway about how transitional arrangements will be handled for students yet to complete the course at the time new arrangements are introduced.

When given the opportunity to review the current training framework, a host of opportunities presented themselves. CAR, for example, considered centralizing all assessments but concluded the evidence did not justify such a step and the creation of Bar assessment guidelines and Lead External Examiners would ensure the high standards required to guarantee the protection of the public. Driving the approach to change was the focus on day-one outcomes as recommended by LETR and as defined in the Professional Statement. As with all reviews of barrister training over the past 20 years, the system in place is considered fit for purpose and appropriate to the needs of the profession, with only some minor evolutionary amendments were required to help ensure the training landscape for the bar is contemporary.

$51 \quad$ BSB seeks views on draft of new Bar Training Rules, <https://www.barstandardsboard.org.uk/media-centre/press-releases-andnews/bsb-seeks-views-on-draft-of-new-bar-training-rules/ > accessed 20 ${ }^{\text {th }}$ September 2018. 